\title{
Blaž Božič
}

\section{Nepremagljivi Herkuli: italijanska peplum kinematografija}

Namen tega prispevka je predstaviti pojav t.i. peplum kinematografije ob nekaj izbranih vidikih. Pri peplumu gre za specifično zvrst filma in obdobje v zgodovini italijanske povojne kinematografije; za kulturni produkt 20. stoletja, ki je neposredno navdihnjen $z$ antiko. Izbrani vidiki, ki služijo kot ogrodje tega orisa, so problemski in ponujajo iztočnice za nadaljnje razmišljanje, predvsem v okviru recepcijskih, socioloških in estetskih študij. Nekatere značilnosti peplu$m a$, na primer spektakularnost, medsebojna kontaminacija mitoloških vsebin ali kult fizične moči, se seveda ponujajo kot možne iztočnice za interpretacijo $\mathrm{z}$ vidika dialoga $\mathrm{z}$ antiko, druge, na primer trash estetika, pa so predvsem pojav 20. stoletja in pripadajo polju tako imenovane popularne kulture. Tu bo govora o pojavu na sebi, torej o peplumu kot o produktu okoliščin, specifičnih za 20. stoletje. Mednje sodi zlasti razmah kinozabave kot dela tako imenovane popularne ali masovne kulture, ki črpa iz zapuščine klasične antike.

Izraz peplum označuje filmski žanr $\mathrm{z}$ antično tematiko, ki je prevladoval $\mathrm{v}$ italijanski filmski industriji v drugi polovici petdesetih let in prvi polovici šestdesetih let 20 . stoletja. To velja izpostaviti, saj se isti izraz včasih rabi tudi za kateri koli film z antično (in deloma tudi biblijsko) tematiko. Oznaka peplum izhaja iz latinskega prevoda grške besede $\pi \dot{\varepsilon} \pi \lambda$ os (slednji označuje dolgo ogrinjalo, ki so ga nosile ženske v antični Grčiji do 5. stoletja pr. n. š.) in v kontekstu omenjenih filmov referira na kratko krilo, ki ga nosijo junaki, in tako razkrivajo svoja mišičasta telesa. ${ }^{1}$ Peplum se tako včasih uporablja kot sinonim izraza kostumska drama ali angleškega sword and sandal, torej oznak, ki pojmujejo zgodovinski, epski, spektakularni film v širšem smislu in se ne nanašajo zgolj na italijansko produkcijo.

Vrhunec priljubljenosti so ti filmi doživeli v obdobju med letoma 1957

1 Günsberg, »Heroic Bodies«, 97. 
in 1965, ko so italijanski filmski studiji kot Filmar, Romana Film, La Titanus in Glomer posneli okoli tristo nizkoproračunskih filmov z antično tematiko. Obdobje pepluma je nasledilo neorealistični cikel (režiserji Vittorio de Sica, Roberto Rossellini, Luchino Visconti in Frederico Fellini) in predhajalo cikel špageti oz. italo vesterna, ki se je sredi šestdesetih let razmahnil predvsem pod vplivom režiserja Sergia Leoneja.

Ti filmi so nastajali kot poskus imitacije visokoproračunskih ameriških produkcij, kot so bili Kubrickov Spartak (1960) ali DeMilleovih Deset zapovedi (1956), vendar v okviru zelo nizkih proračunov; to so bili filmi, ki so se snemali izključno za zabavo občinstva, za hitro in široko potrošnjo. Pri produkciji je bil poudarek predvsem na kvantiteti in ne kvaliteti. Produkcija je zajemala značilne postopke: na istih lokacijah se je snemalo tudi po več filmov hkrati ali uporabljalo že obstoječo scenografijo, ki so jo pred tem postavili za hollywoodske produkcije. Posluževali so se tudi snemanja predlog, torej tipičnih scen, ki bi jih bilo možno uporabiti v čim večjem številu filmov. Še posebej monumentalne prizore, za katere je večinoma primanjkovalo sredstev, so tako sneli ali »vzorčili« iz večjih produkcij. Kot primer lahko navedemo film 79 n. št., uničenje Herkulaneuma iz leta 1962, ki vsebuje prizor iz filma Zadnji dnevi Popejev (1959). ${ }^{2}$ Neredko se je take scene posnelo pred samim nastankom določenega scenarija: $v$ takšnih primerih so posneli zgolj sceno in naknadno sinhronizirali zvok. Lep primer tipičnih/serijskih scen so filmi Pietra Franciscija. Tako se filmi Herkul (1958), Herkul, Samson in Odisej (1963) in Obleganje Sirakuz (1960) vsi pričnejo s prizorom pastirja oziroma ribiča, ki igra na Panovo piščal. V številnih filmih se pojavi tudi podobni ali identični prizori skupine deklet, ki zbežijo ali jih nekdo odslovi (filmi Sapfo, Venera $z$ Lezbosa, Herkul, Herkul, Samoson in Odisej, Obleganje Sirakuz). ${ }^{3}$ Preusmeritev v snemanje vesternov, ki jo je filmska industrija napravila sredi šestdesetih let, je v tem smislu pomenila zgolj spremembo snovi. Špageti vesterni so namreč povečini sledili istima principoma, nizkoproračunskosti in serijalnosti, ob tem pa so pravzaprav še naprej uporabljali isto naracijo in iste like, le da so bili ti zdaj postavljeni v kontekst divjega zahoda.

Osrednja junaka pepluma sta gotovo Herkul in Maciste. ${ }^{4}$ Herkul jasno aludira na junaka iz grške mitologije, seveda z glavno lastnostjo, ključno za njegov prikaz v peplumih, ki je fizična moč. To je pravzaprav bistvo vseh junakov, ki se pojavijo v teh filmih. Maciste je v tem smislu nekakšna abstrakcija Herkula: gre za junaka, ki je odrešen svojih mitoloških konotacij, je arhetipski junak $\mathrm{z}$ glavnim atributom fizične moči, podobno kot sta $\mathrm{v}$ špageti vesternih

2 Štefančič, Ubij vse in vrni se sam, 18.

3 Screenshoti teh prizorov so dostopni na naslovu http://www.peplumtv.com/p/the-films-ofpietro-francisci.html (zadnjič obiskano 24. 8. 2015).

4 Drugi junaki, ki se pojavljajo, so Ursus (lat. »medved«), prav tako arhetipski junak z jasno aluzijo na fizično moč, ki se je sicer prvič pojavil v filmu Quo Vadis? iz l.1913 in temelji na istoimenski literarni predlogi H. Sienkiewicza iz 1. 1895, liki iz grške mitologije (Odisej, Tezej, Ahil, Ajant) ter zgodovinske (Spartak) in biblijske osebnosti (Samson, Goljat). 
arhetipska junaka »mož brez imena« ali Django. Maciste je torej »serijski junak«, ki (tako kot Herkul) ni vezan na čas in kraj in se prav tako pogosto pojavlja v zgodbah, znanih iz grške mitologije, kot se pojavlja v Rimu, ali skupaj z Vikingi, Mongoli, Inki in nezemljani.

Prvi filmi z Macistom se pojavijo že v času nemega filma, v dvajsetih letih 20. stoletja. Takrat ga je igral Bartolomeo Pagano - prvi film z likom Macista, silnega sužnja, je bil film Cabiria (1914). Pagano je Macista igral v številnih nadaljevanjih še nadaljnjih štirinajst let (in se tudi uradno preimenoval v Macista!). Prvemu razmahu priljubljenosti teh filmov je botrovala tudi istočasna popularnost stripov fumett ${ }^{5}$ in dolga tradicija fascinacije nad mišičnjaki v kontekstu cirkusa ali javnih nastopov na trgih. Izumitelj tega lika, Gabriele D’Annunzio, ki je kot scenarist oziroma avtor mednaslovov sodeloval pri nastanku filma Cabiria, ime navaja kot enega od Heraklovih epitetiov. ${ }^{6}$ D’Annunzio, pesnik, pisatelj in publicist, je bil v tistem času pomembna javna figura in je v italijanski družbi užival velik ugled. Po prvi svetovni vojni je imel s svojimi idejami in svojo pojavo precej močan vpliv na Benita Mussolinija. Tako je znano, da se je Mussolini v govorih opiral na njegov retorični slog, prav tako so se D’Annunziove močno nacionalistične in z italijanskimi ozemeljskimi zahtevami povezane ideje zrcalile v Mussolinijevem političnem programu. Lik Macista sicer nikoli ni bil eksplicitno uporabljen v propagandni kinematografiji (ki se je v fašistični Italiji ni začela pred letom 1937), vendar, kot ugotavlja Aimee Pavy v svojem eseju o Macistu, ${ }^{7}$ njegov lik popolnoma ustreza fašističnim idealom telesne sposobnosti in patriarhalne moči. Podobnost med Paganom/Macistom, ki je do sredine dvajsetih let postal izredno priljubljen lik, in Mussolinijem, lahko razberemo iz filma Maciste imperatore (1924), kjer Maciste uporablja fašistične poze in gestikulacijo, medtem ko je Mussolinijeva pojava, obratno, spominjala na Macista: ${ }^{8}$ bil je odločen, telesno močan, priznaval je nasilje kot sredstvo za doseganje ciljev in se razglašal za zaščitnika nemočnih. V kontekstu vloge, ki je pripadla D’Annunziu in jasne samoidentifikacije zgodovinskega fašizma $\mathrm{z}$ rimskim cesarstvom, je ta relacija v smislu herkulskega »javnega telesa « (to sta bila tako Mussolini kot Pagano) gotovo močan ideološki moment pepluma, telo samo pa pomemben del fašistične ikonografije.

Med prvim in drugim - glavnim - valom v šestdesetih skorajda ni bilo nobenih filmov $\mathrm{z}$ antično tematiko, pojavljali so se zgolj sporadično (npr. Scipione l'Africano, 1937), v petdesetih letih pa se je pričel drugi, glavni val pe-

5 Günsberg, »Heroic Bodies«, 98.

6 Prim. Woodard, Cambridge Companion to Classical Greek Mythology, 477, pa tudi Smith, A Dictionary of Greek and Roman Mythology, ki navaja ime Mákı "najvišji «) kot enega od Heraklovih epitetov v lokalnem kultu v mestu Makistos v Elidi; gl. tudi

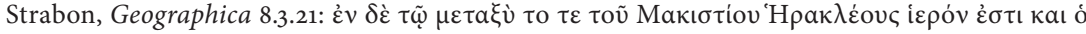

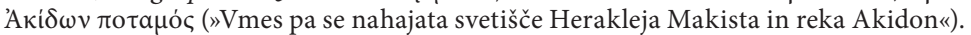

7 Dostopno na naslovu http://www.silentfilm.org/archive/maciste-1915 (zadnjič obiskano 15. 12. 2015).

8 Gundle, Mussolini's Dream Factory, 44. 
pluma. Filmi so se snemali ne samo za italijanski trg, ampak tudi in predvsem za izvoz. Ker je prevladovalo ameriško tržišče, so si italijanski igralci, ki so računali na večjo prepoznavnost, pogosto nadevali ameriška imena. Tako je Sergio Cianni postal Alan Steel, Adriano Bellini pa Kirk Morris. Prav tako so prilagajali naslove in imena filmskih likov. Filmom, v katerih je nastopal Maciste, so v verziji za mednarodni trg pogosto dajali naslove $z$ bolj znanimi junaki (praviloma je šlo za dobro znane figure iz grške mitologije), zvok pa so seveda sinhronizirali v angleščino. Zgovorno je dejstvo, da je film Le fatiche di Ercole (1957), ki so ga sinhronizirali v angleščino in ga naslovili Hercules, po ameriških kinodvoranah krožil s šesto kopijami, medtem ko jih je bilo v Italiji v obtoku manj kot trideset. Produkcija pepluma, ki je leta 1958 zajemala le $4 \%$ celotne italijanske filmske produkcije, je do leta 1961 narasla na 13\%, nato rahlo upadla in leta 1963 doživela vrhunec s $15 \% .{ }^{9}$ Najbolj znani režiserji so bili že omenjeni Pietro Francisci, nadalje Mario Bava, ki se je kasneje preusmeril v snemanje grozljivk, Vittorio Cottafavi in Riccardo Freda.

Glavne junake so igrali skoraj izključno bodibilderji. Ti bodibilderji, z najbolj znanim Stevom Reevesom na čelu, so bili sprva »uvoženi«iz Amerike. Reeves je z zgodnjimi filmi, med katere sodita La fatiche di Ercole (1957) in Ercole e la regina di Lidia (1957), opredelil podobo tipičnega herkulskega junaka pepluma. Bodibilderji, ki so sledili v nadaljnjih peplumih in igrali bodisi Herkula, Macista, Tezeja ali kogar koli drugega, so sledili njegovemu zgledu. Tako kot je programski glavni junak pepluma, so programske tudi naracija, scenografija in pričakovani psihološki vpliv, ki naj bi ga film imel na gledalce. Slednje je še posebej zanimiv fenomen. Znano je namreč , da je denimo Duccio Tessari postavil številna pravila, ki so natančno določala pričakovani odziv občinstva. ${ }^{10}$ Peplum se nam skozi ta dejstva kaže kot popolnima formulaičen in tog žanr.

\section{TELO IN MOČ}

Ker so bila pričakovanja producentov tako natanačno opredeljena, se zdijo nadvse smiselne interpretacije Maggie Günsberg, ki se vizualnih in narativnih momentov pepluma loteva skozi prizmo spola. Osrednji lik pepluma je vedno mišičast moški, junak, ki se loči od ostalih ljudi (oz. telo, ki se loči od ostalih, inferiornih teles; to poteka narativno, z junakovo zavrnitvijo družinskega okolja in vizualno, $\mathrm{z}$ nasprotjem med delujočim telesom in statičnimi telesi.) ${ }^{11}$

Znotraj Italije se je peplum distribuiral v glavnem v t.i. terza visione kinematografih $^{12}$ na jugu Italije; $v$ teh kinih so bile vstopnice naprodaj po nižjih

9 Günsberg, »Heroic Bodies«, 100.

10 Ibid.: 103.

11 Ibid.: 108-110.

12 Medtem ko so se v prima visione vrtele visokoproračunske produkcije, so v seconda in terza visione kinih vrteli nizkoproračunske filme (prim. pojem B kategorija). 
cenah. Publika je bila večinoma nižje izobrazbe, šlo je za delavce ali za kmete. Osrednji prizor, pretepaška scena, v kateri junak izključno s svojo fizično močjo premaga zlobneža, je ponudil afirmacijo mišičastega telesa, ki je v delavskih in ruralnih okoljih pomenilo eno glavnih vrednot - v nasprotju $\mathrm{z}$ intelektualno močjo, ki se jo razume kot značilnost t.i. višjih slojev. Ta vidik razkriva torej identifikacijo skozi pripadnost določenemu družbenemu sloju.

Še posebej se mi zdi tu pomembno izpostaviti motiv »trpečega telesa «. ${ }^{13}$ To je junakovo telo, ki je podvrženo preizkušnji, v kateri pride do izraza njegova fizična moč. Za trenutek se nam zdi, da junak izgublja, ko trpi pod udarci nasprotnika; junak se napreza, ko podira stebre ali z golimi rokami upogiba kovinske palice. To je bistvo junaštva tudi v mitografskih predlogah tipičnega junaka pepluma: tu lahko potegnemo jasno vzporednico s Heraklovimi deli to so dejanja, ki jih navaden človek ne bi mogel nikoli opraviti, terjajo namreč junaka $\mathrm{z}$ nadčloveškimi močmi.

$\mathrm{V}$ smislu vizualnega prikaza, torej konkretne slike, ki jo vidimo na platnu, pa je prav ta trenutek tisti, ki razkrije »estetskost « tega telesa - trpeče telo je vrhunec delujočega telesa, telesa $\mathrm{v}$ akciji: vidimo napete mišice, preznojeno telo in značilne izraze na obrazu. Posnetki so pogosto iz prvega plana, so zelo natančni, velikokrat se metonimično pojavijo samo posnetki mišic. Kmalu po tem trpljenju junak premaga nasprotnika ali prestane preizkušnjo. Ta prizor ponudi osrednji imago pepluma: poenoteno in reprezentativno podobo junaka (ne glede na to, ali mu je ime Maciste, Herkul ali Goljat), ki jo lahko razumemo kot osrednjo točko identifikacije.

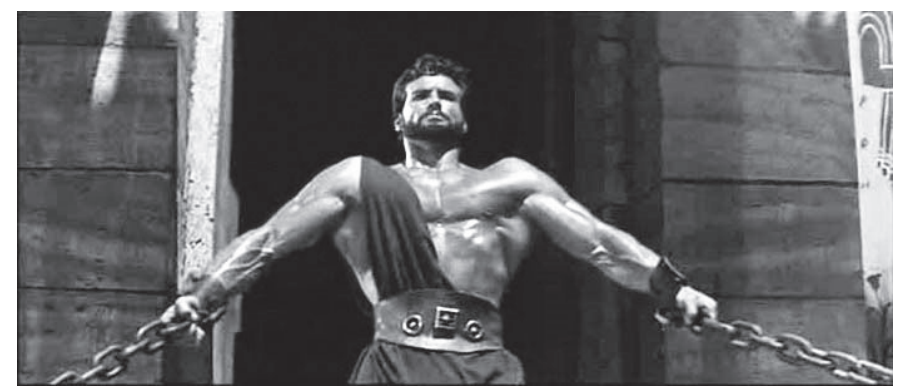

Slika 1: Steve Reeves, »trpeče telo« v filmu Ercole e la regina di Lidia (1958); vir: www. peplumtv.com (zadnjič obiskano 27. 8. 2015).

Za interpretacijo skozi prizmo spola, ki ji sledi M. Günsberg, je pomemben tudi moment »reševanja nemočne osebe«; ta oseba je v peplumih izključno ženskega spola. Če se že zgodi, da ženska rešuje moškega, to po pravilu vedno spodleti. V filmu La fatiche di Ercole (1957) tako Io skuša rešiti Herkula iz ječe: uspe jima odpreti vrata, toda ta se potem spet zapahnejo in zaprejo tudi njo.

13 Pogosto je ta moment najbolj viden v osrednjem pretepaškem prizoru, na primer v filmu Herkul, Samson in Odisej (1963). 
Herkul se nato sam osvobodi okovov in reši oba. Ta moment naracije odpre še dodatno razsežnost, ki jo nosi motiv fizične moči, namreč moč, ki določa razmerje med spoloma.

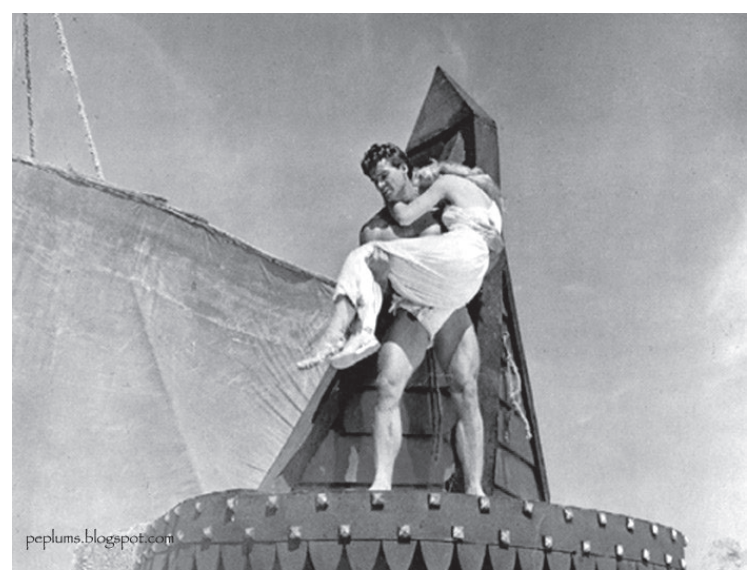

Slika 2: Junak rešuje nemočno žensko; vir: www.karwansaraypublishers.com (zadnjič obiskano 27. 8. 2015).

M. Günsberg nam tako ponuja možno interpretacijo fizične moči kot afirmacije tradicionalnih razmerij med moškim in ženskim: naracija, v kateri glavni junak s svojo fizično močjo premaga zlo in reši nemočno žensko, vzdržuje patriarhalni družbeni red. Interpretacija se zdi povsem upravičena tudi $\mathrm{v}$ zgodovinskem kontekstu nastanka pepluma (petdeseta in zgodnja šestdeseta leta, torej čas pred seksualno revolucijo in pričetkom emancipacije med spoloma) in v luči obstoja Tessarijevih precej mizoginih pravil snemanja peplumov. ${ }^{14}$

Nadalje je v številnih peplumih pomemben element naracije - ki junakovo telo loči od ostalih teles - njegova ločitev od domačega okolja. To omogoča (samo)identifikacijo junaka kot junaka; on sam se namreč zavestno loči od sfere pasivnosti, varnosti, od družinskega okolja, ki ne dopušča razvoja njegove junaškosti. Vizualno, na platnu, se po tem trenutku ločitve junak pogosto prikaže na potovanju po divjini, po odročnih krajih, iščoč vedno nove izzive in preizkušnje ter spopade v imenu dobrega. ${ }^{15}$ Ker se sfero domačega doma in pasivnosti po tradiciji povezuje $\mathrm{z}$ ženskim, služi v tem smislu tudi ta moment diferenciaciji moške in ženske sfere. ${ }^{16}$

Fetišiziranje telesa $\mathrm{z}$ značilnim postopkom metonimije, kot je vidno denimo pri posnetkih mišic iz bližnjega plana, pogosto $\mathrm{v}$ momentu »trpečega telesa «, pa ponuja tudi interpretacijo telesa kot idealizirane podobe moškosti.

14 Günsberg, »Heroic Bodies«, 103.

15 Junak pepluma je v bistvu kasnejši junak špageti vesterna (Django ali »mož brez imena«).

16 O tem Hartsock, Money, Sex and Power. 
Telo, ki ga je prvi definiral Steve Reeves, je v vsakem primeru umetno oblikovano telo: tudi občinstvo, na katerega so ti filmi merili in ki mu je fizična moč pomenila vrednoto, se je ob gledanju pepluma neizbežno soočilo $s$ fantastičnim junakom, katerega mišičasto telo ima absurdne razsežnosti (na primer, podira stebre), in je tako gotovo trčilo ob mit ter se tega tudi zavedalo. ${ }^{17}$ Tako kot antični polbogovi z nadnaravno močjo živijo v močnem času, živijo junaki pepluma na filmskem platnu.

Po drugi strani je ta kult telesa seveda osnovan na realnih tleh. Zlahka opazimo, kako se je v peplum filmu odražal tudi povojni kulturni promet med Ameriko in Italijo. Te filme je seveda možno brati kot željo po izoblikovanju mišičastega telesa ali po umetnem ustvarjanju le-tega. Tu se gotovo odraža trend bodibildanja, ki je $\mathrm{v}$ tridesetih in štiridesetih letih $\mathrm{v}$ Ameriki doživel svojo zlato dobo $\mathrm{z}$ množičnim razmahom telovadnic, revijami za bodibildanje in s pojavi, kakršna sta bila tekmovanje za Mister America (prvič so ga izvedli leta 1939) in tako imenovana Muscle Beach v Santa Monici, kjer so bodibilderji razkazovali svoja telesa pred navdušeno publiko.

Italijanski filmarji so sprejeli ta trend, ga premestili v antično okolje, s katerim so se identificirali, in ga kot izvozni artikel ponovno ponudili Ameriki. Arhetip junaka, ki je nekakšen križanec med figuro iz antične mitologije in bodibilderja s plaže v Santa Monici, je v Ameriki kmalu zatem, ko so jo dosegli prvi peplumi, pričel krasiti naslovnice revij American Weekly, Life, Silver Screen itd. $^{18}$

\section{SPEKTAKEL}

Tessarijevo pravilo, da je v peplumu "treba uporabiti veliko ognja in dima«, češ da so »žerjavica, goreči šotori in plameneče sulice so vredne več kot vsak dialog «, ${ }^{19}$ dobro povzema še enega izmed konstitutivnih elementov tega filma. Zgodba je sekundarnega pomena, $v$ ospredju sta vizualnost in prikaz: pomembno je vse, kar bi pritegnilo gledalca, željnega zabave, sprostitve in predvsem spektakularnosti. Sem sodijo kaskaderski kadri, akcijske scene, razkošni kostimi, »eksotičnost « oddaljenih krajev in časov in tako dalje. V tem smislu pri peplumu ne gre za umetnost, niti za žanrsko, saj se je tovrstne filme snemalo izključno za čim obsežnejšo potrošnjo. So lep primer kinematografa kot prostora porajajočega se fenomena masovne kulture, ki se je v 20. stoletju razvijala skupaj z novimi mediji, sposobnimi dosegati velike množice ljudi. Film v petdesetih letih prejšnjega stoletja sicer ni bil nov medij, je pa kinokultura takrat doživela poln razmah.

17 Zanimivo bi bilo raziskovati, v kolikšni meri je ta idealizirana podoba prav zaradi tega absurda, ki je nam danes očiten, delovala parodično pri občinstvu iz petdesetih let.

18 D’Amelio, »The Hybrid Star«, 274.

19 Günsberg, »Heroic Bodies«, 104. 
Obisk kinodvorane je postajal čedalje pogostejša oblika preživljanja prostega časa. Čeprav je v kontekstu filma, književnosti, likovnosti, glasbe in podobnega izredno težko ločevati med »umetnostjo « in »ne-umetnostjo «, lahko morda za silo potegnemo takšno ločnico, če upoštevamo kriterij namembnosti dela. ${ }^{20}$ Gledalec ne vstopi v kinodvorano gledat peplum, ker bi si želel (recimo temu tako) »umetniške izkušnje«, ampak zato, da bi se sproščal in zabaval ob gledanju čim bolj spektakularnih prizorov. Antika je s svojo »eksotiko « in široko razširjenimi stereotipi, med katere sodijo pompozni rimski triumfi, razkošna oblačila, silni mitološki junaki, spektakularne bitke, seveda nudila nadvse primerno snov.

Prav tako je pomemben razvoj tehnike: barvni filmi v tehnikolorju so $\mathrm{v}$ petdesetih letih doživeli razmah in omogočali dokaj realistične prikaze (še posebej seveda pretepov) z bližnjimi plani in podrobnimi prikazi mišičastega telesa. Čeprav prizori delujejo razkošno, pa je pravzaprav tudi vizualna naracija preprosta in lahko doumljiva.

V kontekstu spektakularnosti je zlasti vredno omeniti "podžanr « gladiatorskega filma, kjer prihaja akcijski moment še posebej do izraza. Ogled pepluma v 20. stoletju in ogled gladiatorskih iger v antičnem Rimu sta imela podobno funkcijo - ponujala sta spektakel in zabavo, dostopno tudi najnižjim slojem. ${ }^{21}$ Zato lahko zlahka potegnemo vzporednico med antično areno in moderno kinodvorano; fascinacija nad nasiljem antične rimske družbe v kontekstu krvavih javnih iger in fascinacija nad nasilnimi prizori znotraj filma sta obširni temi, za kateri tu ni prostora. Vsekakor pa je dejstvo, da peplumi sodijo med filmske žanre, v katerih igra nasilje osrednjo vlogo. Čeprav obstaja razlika med naracijo pepluma in "naracijo « gladiatorske igre v antičnem Rimu - smrt gladiatorja je v kontekstu iger munera pomenil vrhunec dogodka, medtem ko $\mathrm{v}$ tipičnem gladiatorskem peplum filmu osrednji junak ne umre, saj je uporen, zoperstavlja se denimo zlobnim cesarjem in na koncu zmaga,$-{ }^{22}$ je za občinstvo kontekst, v katerem pride do soočenja s smrtjo in nasiljem, morda isti. Tako kinematograf kot arena sta pomenila kanalizirano nasilje, v smislu ogleda filma ali gladiatorske igre torej neki obred, v katerem so bili ljudje dovolj odmaknjeni. Oba konteksta sta namreč morala do neke mere učinkovati nerealno - za ogled filma to seveda velja v večji meri, vendar je tudi v areni ločenost publike od prostora, kjer je potekal boj na življenje ali smrt, morda $\mathrm{v}$

20 Vendar tudi takšno ločevanje skriva pasti. Če nič drugega, se lahko kaj hitro ujamemo v redukcionistično vrednostno dihotomijo (tako kot sta se denimo v glasbenih krogih uveljavila termina resna in zabavna glasba s povsem neustreznimi vrednostnimi implikacijami). Peplum lahko morda, skozi oči današnjega gledalca, vidimo kot nekakšno kurioziteto, kot relikvijo nekega specifičnega trenutka filmske zgodovine, podobno kot hongkongški kung fu film ali tako imenovano eighties trash grozljivko, in ji zato zaradi specifične vizualne podobe vsaj do določene mere pripisujemo vrednost tudi v umetniškem smislu, oziroma jo estetiziramo.

21 Čeprav ne samo izključno te. Tako so bila t. i. munera, ki so poleg gladiatorskih iger vključevala tudi obredne usmrtitve in lov na živali, seveda tudi politični instrument, ki je vzdrževal odnose med vladarjem in podaniki.

$22 \mathrm{~V}$ tem smislu tudi novejše hollywoodske produkcije, npr. Gladiator Ridleya Scotta iz leta 2000. 
psihološkem smislu, če si dovolimo spekulacijo, pomenila dovolj veliko pregrado. Na platnu lahko podoben psihološki moment opazimo tudi pri drugih »nasilnih « žanrih, na primer pri grozljivkah in vojnih filmih. Prav tako - to je pomembno izpostaviti - v peplumih smrt na platnu vedno vsebuje moralno komponento: smrt antagonista je seveda vsakič upravičena, smrti pozitivnih likov je malo in te imajo navadno točno določeno funkcijo. Služijo zapletu v zgodbi in se na koncu razrešijo (na primer, pride do maščevanja). Identifikacija $\mathrm{v}$ smislu dobrega in zla igra $\mathrm{v}$ peplumih pomembno vlogo. Tessarijevo pravilo pravi: »Občinstvu mora biti takoj jasno, s katerimi liki mora držati. $\ll^{23} \mathrm{~V}$ tem okviru Tessari opredeljuje celo barve oblačil, ki naj bi olajšale to odločitev: tako rumena in bela barva kažeta na pozitivni lik, medtem ko črna ali rdeča kažeta na negativnega. ${ }^{24}$

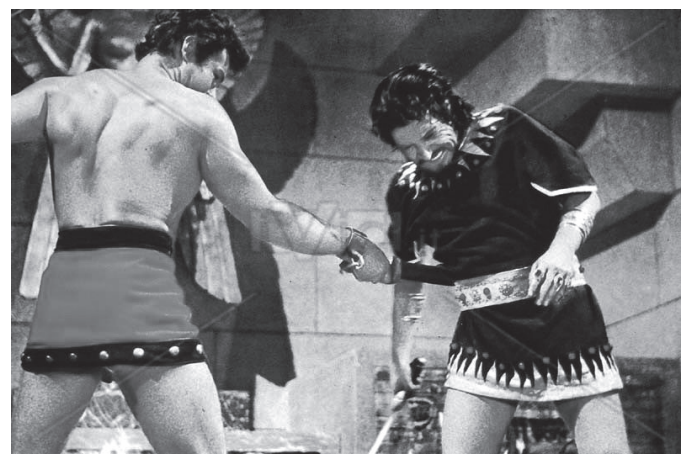

Slika 3: Smrt na platnu, prizor iz filma L'ultimo gladiatore (1964); vir: www.ivid.it (zadnjič obiskano 27. 8. 2015).

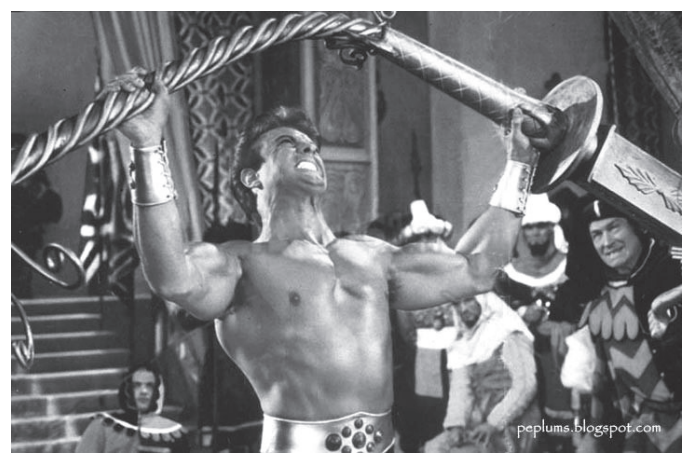

Slika 4: Bližnji plan mišičastega telesa; vir: www.peplumtv.com (zadnjič obiskano 27. 8. 2015). 


\section{KONTAMINACIJA}

Čeprav je naracijska zgradba tipičnega pepluma popolnoma šablonska in kot taka zgolj nekakšna kulisa za vizualni del, ki je, kot rečeno, venomer v osredju, pri obravnavi snovi vendarle obstaja postopek, ki ima svojo specifiko: snov, v prvi vrsti vzeta iz antične mitologije in $v$ manjši meri iz zgodovine, se je pogosto mešala s snovjo iz drugih kontekstov in/ali $z$ drugimi žanri. $S$ takšnim postopkom se je seveda dosegalo še večjo spektakularnost, večjo nenavadnost in eksotiko, ki je gotovo pritegnila številne gledalce. ${ }^{25}$ Pogosto je križanje znotraj antičnega konteksta: junaka iz grške mitologije se je tako postavilo v kontekst antičnega Rima ali pa se je rimske like postavilo v kontekst grške mitologije. Tako naletimo na zgodbo o gladiatorju, ki reši Heleno iz Troje in jo odpelje v Tebe, o dveh gladiatorjih, ki se vrneta iz trojanske vojne in pristaneta pri Amazonkah, ali na zgodbo o Herkulovem sinu Pozejdonu, ${ }^{26}$ ki rešuje kristjane pred rimskim pogromom. ${ }^{27}$ Dogajalo se je tudi, da so se različne mitološke (in književne) predloge prepletale med seboj; tako se je Herkul lahko znašel na Atlantidi (v filmu Ercole alla conqiuista di Atlantide, 1961).

Obstajajo tudi številni primeri mešanja $\mathrm{z}$ žanroma grozljivke in znanstvene fantastike: Herkul se je bori proti nezemljanom z Lune, Maciste oz. Golijat pa se v filmu Maciste proti vampirju (Maciste contro il vampiro, 1964) spopade z vampirji, medtem ko se Herkulov sin oz. Maciste za časa ledene dobe spoprime z ognjenimi pošastmi (Maciste contro i monstri, 1961).

$S$ temi trans-zgodovinskimi avanturami se glavni liki potrjujejo kot brezčasovni, brezkontekstni junaki: Herkul (oz. Samson v izvirni, italijanski verziji) lahko pristane pri Inkih in jim pomaga strmoglaviti tirana, na primer $\mathrm{v}$ filmih Herkul in Zaklad Inkov (Sansone e il tesore degli Incas, 1964) in Herkul proti sinovom sonca (Ercole contro i figli del sole, 1964), kar je enako absurdno kot Herkul oz. Maciste, ki pomaga poljski vojski ubraniti se pred Džingiskanovimi mongolskimi hordami v filmu Herkul proti barbarom (Ercole nell'inferno di Gengis Khan, 1964).

Pri mešanju historičnih obdobij, mitoloških ciklov ter mitologije z zgodovinskostjo in z realnim ne gre za psevdohistoričnost, ampak za neobremenjen postopek mashupa v smislu snovi in crossbreeda v smislu žanra. ${ }^{28}$ Maggie Günsberg tako po mojem mnenju povsem upravičeno peplum opredeli za fantazijski film. ${ }^{29}$

25 Danes ta mashup estetika seveda deluje absurdno, parodično, in je, v retrospektivi, gotovo ena izmed najbolj značilnih komponent pepluma; parodičnost Günsberg, op. cit., 1. 97, razume kot enega konstitutivnih elementov pepluma kot samostojnega žanra. Hkrati je ta estetika eden izmed razlogov, da peplum danes znotraj filmske zgodovine obravnavamo kot kurioziteto.

26 »Herkulov sin« je še ena različica standardnega junaka, tako kot Maciste, Ursus itd.

27 Štefančič, Ubij vse in vrni se sam, 18-19.

28 Pojma mashup in crossbreed sem vzel iz glasbenega žargona. Pri prvem gre za spajanje že ustvarjenih pesmi v novo celoto, na primer vokalnega dela ene pesmi s podlago iz druge; torej za spajanje diskretnih sistemov. Pri drugem gre za žanrsko križanje, za ustvarjanje hibridnih zvrsti, ki ohranjajo značilnosti obeh/vseh uporabljenih žanrov.

29 Günsberg, »Heroic Bodies«, 97 


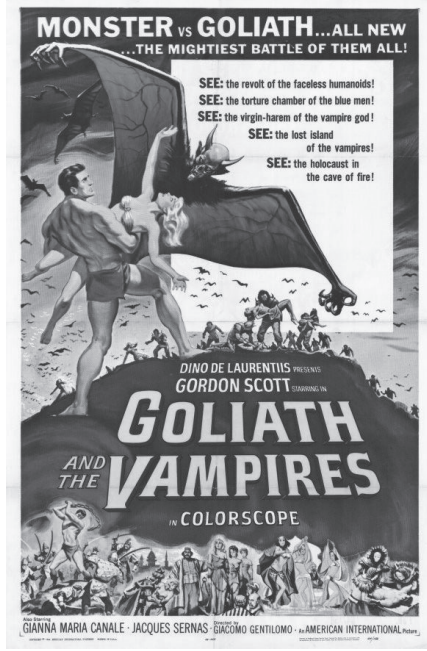

Slika 5: Plakat za film Golijat in vampirji, primer križanja z žanrom grozljivke; vir: www.moviepostershop.com (zadnjič obiskano 27. 8. 2015).

\section{SKLEP}

Peplum si zaradi specifičnega postopanja pri obravnavi snovi, pa tudi z vidika vizualne estetske podobe vsekakor zasluži obravnavo kot samostojen žanr znotraj filmske zgodovine. Ločevati ga je treba od zgodovinskega filma, saj si za razliko od slednjega ne prizadeva za nikakršno »avtentičnost « pri prikazu zgodovine ali pri obravnavi mitološkega izročila; določeno »avtentičnost«napram izročilu, iz katerega črpa, lahko malce paradoksalno vidimo prav v tem križanju in sprejemanju elementov iz drugih (filmskih in mitoloških) izročil: nedogmatskost in odprtost za vplive od drugod je namreč tudi značilnost grškega mita.

Peplum odpira mnoga vprašanja tudi na področjih zunaj filmske zgodovine. Tako je vsekakor ključna obravnava glavnega lika in njegova herkulska ikonografija: ta tema je bila v novejšem času deležna številnih obravnav znotraj študij spola, prav tako je zanimiva $\mathrm{v}$ kontekstu povezav z zgodovinskim fašizmom v Italiji, vsaj kar se tiče prvega vala pepluma s filmom Cabiria (1914) in posredništvom D’Annunzia.

Peplum kot žanr lahko po svojem bistvu še najlažje vzporejamo z njegovim naslednikom, tj. s špageti vesternom, ${ }^{30}$ vsaj kar se tiče naracije, značilnosti glavnega lika in namembnosti pri produkciji.

Filmi $z$ antično tematiko so se snemali vseskozi, vendar lahko upravičeno trdimo, da je prav obravnavani, drugi val pepluma najmočnejši; sledil je zgledu posameznih ameriških filmov $\mathrm{z}$ antično tematiko in trendu bodibildanja ter pripomogel $\mathrm{k}$ njegovi popularizaciji. Prav tako ne more biti govora o peplumu

30 Številni režiserji so se po koncu obdobja pepluma zlahka preusmerili v snemanje špageti vesternov. Med njimi je bil Sergio Leone, ki se je s svojimi vesterni proslavil bolj kot s peplumi. 
kot o specifično italijanskem pojavu.

V prvem desetletju 21. stoletja smo bili priča ponovni popularizaciji filmov z antično tematiko (začenši z Gladiatorjem Ridleya Scotta iz 1. 2000 in Trojo iz 1. 2002). Čeprav so te produkcije vse prej kot nizkoproračunske in amatersko ali površno posnete, so vseeno zastavljene kot spektakli, ob katerih lahko publika uživa v eksotiki zgodovine in potrjuje svoje stereotipe o antiki. Najizrazitejša sodobna dediča peplum filma pa sta po mojem mnenju filma 300 (iz leta 2006) in The Immortals (2011). Absurdna mišičasta telesa špartanskih junakov in elementi grozljivke, pa tudi neposredna povezava s stripovsko kulturo kažejo na čvrsto zasidranost v peplumski tradiciji.

\section{BIBLIOGRAFIJA}

Cowles, L. »The Spectacle of Bloodshed in Roman Society.« Constructing the Past 12 , št. 1 (2011). Dostopno na: http://digitalcommons.iwu.edu/constructing/vol12/iss1/1o/.

D'Amelio, M. E. »The Hybrid Star: Steve Reeves, Hercules and the Politics of Transnational Whiteness." Journal of Italian Cinema and Media Studies 2 (2014): 259-277.

Gundle, S. Mussolini's Dream Factory: Film Stardom in Fascist Italy. Oxford: Berghahn, 2013.

Günsberg, M. Italian Cinema: Gender and Genre. Houndsmille: Palgrave Macmillan, 2005.

Hartsock, N. Money, Sex and Power: Toward a Feminist Historical Materialism. New York: Longman, 1985.

Hibberd, M. The Media in Italy. Maidenhead: Open University Press, 2008

O'Brien, D. Classical Masculinity and the Spectacular Body on Film: The Mighty Sons of Hercules. Houndsmille: Palgrave Macmillan, 2014

Schenk, I. Film und Kino in Italien. Marburg: Schüren, 2014.

Smith, W. A Dictionary of Greek and Roman Mythology. Ann Arbor: University of Michigan, 2005.

Štefančič, Marcel. Ubij vse in vrni se sam. Ljubljana: UMco d.o.o, 2002.

Woodard, R. D., ur., Cambridge Companion to Classical Greek Mythology. Cambridge: Cambridge University Press, 2008.

\section{UNBESIEGBARE HERKULESSE:}

DIE ITALIENISCHE PEPLUM KINEMATOGRAPHIE

\section{Zusamenfassung}

Der Gegenstand dieses Beitrags sind die sogenannten italienischen Peplum Filme. Es handelt sich hierbei um ein spezifisches Genre und eine spezifische Ära der italienischen Filmgeschichte. Der Peplum ist ein Kulturprodukt des 20. Jahrhunderts, das auf dem Nachlass der klassischen Antike und vor allem auf ihren Stereotypen beruht. Der Peplum bietet neben einer Interpretation 
im Rahmen der Filmgeschichte auch eine Vielzahl von Ausgangspunkten für zahlreiche Forschungsfelder, z. B. der Soziologie, der Ästhetik und der Rezeptionsstudien. Herkules und Maciste, die Hauptprotagonisten dieser Filme, sind Helden, die außerhalb eines Zeit- oder Kontextrahmens bestehen: In den mehr als dreihundert Peplumfilmen, die zwischen 1957 und 1964 gedreht wurden, erscheinen sie so neben Odysseus, Samson oder zusammen mit Inkas, Mongolen und Vampiren. Die gegenseitige Kontamination diverser mythologischer und historischer Kontexte und das unbeschwerte Kombinieren verschiedener Filmgattungen erzeugt ein parodisches, spektakuläres Genre, das sich keineswegs um 'Authentizität' oder um Treue gegenüber der Tradition, aus der sie ihren Stoff schöpft, bemüht. Mit der physischen Kraft als Schlüsselattribut gewährt der herkulesartige Hauptprotagonist ein starkes imago für verschiedene Ideologien, die auf dem Kult der körperlichen Kraft und traditionellen Geschlechterrollen beruhen. 